\title{
CORONAVIRUS DISEASE-19 (COVID-19): THE DISEASE THAT CHANGED THE WORLD
}

\author{
Beliz Koçyiğit, Sezin Sayın, Fevzi Oktay Şişman, Sarper Kızılkaya, Mert Yücel Ayrık
}

Trakya University School of Medicine, Edirne, TURKEY

\begin{abstract}
In December 2019, several cases of severe pneumonia were identified in Wuhan City, the capital of Hubei province. Upon further investigation, the pathogen causing these symptoms was identified and named as SARS-CoV-2 and the disease was given the name COVID-19 by the World Health Organization. Being able to spread rapidly through respiratory droplets and capable of asymptomatic transmission, COVID-19 became a health concern of a global scale in a matter of months. The most common signs and symptoms of COVID-19 patients at hospital admission are fever, dry cough, and dyspnea. Most people experience the disease with mild symptoms but in more severe cases these can develop into pneumonia and acute respiratory distress syndrome. In this review, we aim to summarize the current information over COVID-19 and its causative agent SARS-CoV-2.
\end{abstract}

Keywords: COVID-19, SARS-CoV-2, pandemic

\section{INTRODUCTION}

Coronavirus disease-2019 (COVID-19) is an infectious disease caused by the most recently discovered severe acute respiratory syndrome coronavirus- 2 (SARS-CoV-2) (1). The disease was first identified in December 2019 in Wuhan, Hubei Province in China as cases of pneumonia of unknown etiology (2). Most of the initial cases were epidemiologically linked to the Huanan seafood market $(2,3)$. Since the identification of early cases in Wuhan, the disease has spread rapidly throughout China in just a few months, inevitably turning into a national public health crisis. As patients presenting the same symptoms have gradually been documented in other countries, World Health Organization (WHO) recognized the outbreak as a Public Health Emergency of International Concern on January 30, 2020 (4). Taking the significant public health risks that the international spread of the disease poses to the world into consideration, the outbreak was declared as a pandemic on March 11, 2020 (5).

\section{VIROLOGY}

Coronaviruses are positive-sense single-stranded RNA genomes that are enveloped and non-segmented. They are $50-200 \mathrm{~nm}$ in diameter (6). Animals are the most common hosts for these viruses, but there are also a few cases in which humans were recorded as the hosts (7). The coronavirus family has four different genera: alpha $(\alpha)$, beta $(\beta)$, gamma $(\gamma)$, and delta $(\delta)$. Only a and $\beta$ can infect humans (8).

Even though many human Coronaviruses (hCoVs) such as hCoV-229E, OC43, NL63, and HKU1 exist, there had only been two incidents of $\mathrm{CoV}$ infections managed to catch the world's attention before the latest outbreak: severe acute respiratory syndrome $\mathrm{CoV}$ (SARS-CoV) and Middle East respiratory syndrome CoV (MERS-CoV). The SARS-CoV outbreak has occurred in 2002 infecting 8422 and causing 916 deaths. The first case of MERS-CoV infection occurred in 2012 and 543 of 1041 infected people have lost their lives due to the outbreak (8).

The SARS-CoV-2 is a zoonotic virus, similar to SARS-CoV and MERS-CoV. Primarily, the Coronaviridae Study Group (CSG) informed that these two viruses model a new species in a new unofficial subgroup of the group Betacoronavirus (1). They were granted specific names as they were the first ones to be identified in their species. SARS-CoV-2 is connected to a previously existing species with many acknowledged viruses usually isolated from humans and hosted by numerous bats. Since the human isolates collected during the 2002-2003 epidemic have been confirmed to

Address for Correspondence: Beliz Koçyiğit, Trakya University School of Medicine, Edirne, TURKEY e-mail: belizkocyigit@gmail.com ORCID: orcid.org/0000-0001-6056-0219

Received: 06.05.2020 Accepted: 03.06.2020 • DOI: 10.4274/tmsj.galenos.2020.07.02.07 Available at: tmsj.trakya.edu.tr 
cause SARS in infected individuals, the names of all these viruses originated from SARS-CoV. The name SARS-CoV-2 was chosen by the CSG by using the entrenched method for identifying viruses in this species and the relationship of the virus to the model SARS$\mathrm{CoV}$ in a species tree (1).

SARS coronavirus of 2002 (SARS-CoV) and SARS$\mathrm{CoV}-2$ are considered to be genetically identical. If these viruses find an animal reservoir that provides a cellular environment that is enough for them to multiply and get advantageous mutations, the virus can infect humans and multiply in human hosts (6).

\section{ORIGIN AND SPREAD}

In December 2019 several cases of severe pneumonia were identified in Wuhan City (9-12). Chinese authorities conducted an immediate investigation of the incident (11). Many of the initial cases were linked to the Huanan wholesale seafood market, in which alive animals such as poultry, dogs, snakes, bats, and fish are traded (9-12). A surveillance system was installed after further cases continued to share a common history of coming into contact with the market (9). On December 31, 2019, China alerted the WHO on the current outbreak. This was followed by the closure of the $\mathrm{Hu}$ anan seafood market the next day (13). The causative agent was later described as a coronavirus that shared over $95 \%$ of its genome with a species of coronaviruses that was commonly found in bats $(12,14)$. Further investigations based on environmental samples indicated the seafood market as the origin of the disease (9). The exponential increase in the number of cases, some of which had never come into contact with the seafood market, indicated that human to human transmission was occurring $(9,11,15)$.

On January 13, 2020, the first case outside of China was reported in Thailand (13). This was closely followed by the initial reports in South Korea and Japan. The occurrence of COVID-19 in these countries on people that have never been to China, supported the concern that the disease could be carried from human to human (15). On January 30, 2020, WHO declared the COVID-19 outbreak as a public health emergency of international concern, explaining that the rapid spread of the disease might pose a risk to the integrity of health systems around the world, especially for countries with vulnerable health systems (13). In the following months, COVID-19 continued to spread around the world. Due to its aggressive spread and high level of severity, COVID-19 was declared a pandemic by the WHO on March 13, 2020 (13).

\section{EPIDEMIOLOGY}

The SARS-CoV-2 has been spreading rapidly since December 2019 and as of April 27, there are 2,878,196 cases and 198,668 deaths according to WHO Situation Report-98 (16).

The source of the SARS-CoV-2 infection can be a previously infected person or object. It can spread by inhaling the droplets that are scattered via coughing and sneezing by infected people. The droplets larger than $60 \mu \mathrm{m}$ in diameter are disposed to drop quickly (17). Furthermore, the virus may spread by one contacting surfaces that were infected and then touching their face, eyes, nose, or mouth before proper handwashing (18).

Individuals with COVID-19 usually begin to show symptoms, including mild respiratory symptoms and fever, 5-6 days after infection (19). The mean incubation period being stated; the incubation period of the SARS-COV-2 varies between 1-14 days (19). The virus can also get spread by asymptomatic patients (20).

Researches have shown that people of all ages can be infected by the SARS-CoV-2. However, older patients, immunocompromised patients, and patients with serious underlying medical conditions such as diabetes, severe obesity (body mass index of 40 or higher), pulmonary diseases, liver diseases, and patients with chronic kidney disease undergoing dialysis are in the high-risk group $(21,22)$. In a study reported by Garg et al. (22) between March 1 and 30, 89.3\% of 178 hospitalized adults had at least one underlying condition. Hypertension (49.7\%), obesity (48.3\%), chronic lung disease (34.6\%), diabetes mellitus (28.3\%), and cardiovascular disease (27.8\%) ranked among the most common underlying conditions. While among the patients aged 18-64 obesity was the most frequent underlying condition, among those aged $\geq 65$ years' hypertension ranked first. In the meantime, hospitalization rates increase with age and $74.5 \%$ of 1482 hospitalized patients were aged $\geq 50$ years $(22)$.

\section{PATHOGENESIS}

The causative agent of COVID-19 is a virus called SARS-CoV-2 (23). The same genome structure and expression pattern are seen among all coronaviruses. They encode 16 nonstructural, 4 major structural [spike (S), envelope (E), membrane (M), and nucleocapsid $(\mathrm{N})$ ] proteins (24). S protein binds to the receptors on the host cell, thereby helping the virus enter the host cell, and is critical for determining transmission capacity and host tropism $(25,26)$. Angiotensin-converting 
enzyme 2 (ACE2) receptor in the respiratory mucosa is one of these receptors (27). According to the literature, 8 of the 14 binding residues directly interacting with human ACE2 in the SARS coronavirus (SARS-CoV) have been preserved in SARS-CoV-2 (28). In addition, the $\mathrm{S}$ protein produced by SARS-CoV-2 was found to have a 10 to 20 -fold higher binding affinity to human ACE2 than the S protein of SARS-CoV (29).

After the virus enters the cells, the viral RNA genome is released into the cytoplasm and the viral genome begins to replicate. Two polyproteins and structural proteins are produced and the newly formed envelope glycoproteins enter the membrane of the endoplasmic reticulum or Golgi apparatus (30). The nucleocapsid is formed by the combination of genomic RNA and nucleocapsid proteins (31). The viral particles then develop into the Endoplasmic Reticulum-Golgi intermediate compartment (ERGIC) (31). Finally, the vesicles containing the virion fuse with the plasma membrane and release the virus (31).

Fever, dyspnea, nonproductive cough, pneumonia, myalgia, fatigue, normal or decreased levels of leukocytes, increased levels of plasma pro-inflammatory cytokines are among the clinical signs of patients with SARS-CoV-2 infections $(15,32)$. Symptoms of COVID-19 are similar to the symptoms of SARS-CoV and MERS-CoV infections (33). The pathogenesis of the disease is mainly presented with severe pneumonia, RNAaemia, ground-glass opacities, and acute cardiac injury (15).

According to the literature, ARDS has been found as the common result of SARS-CoV-2, SARS-CoV, and MERS-CoV infections and is the main cause of death $(15,34)$. Cytokine storm, the overproduction of cytokines by the immune system, causes a violent attack on the body, triggering ARDS and multi-organ failure, subsequently leading to death in severe cases of SARS $\mathrm{CoV}-2$ infections, as in SARS-CoV and MERS-CoV infections $(15,34-37)$.

Patients with COVID-19 showed significantly high blood levels of cytokines and chemokines including IL1-B, IL1RA, IL7, IL8, IL9, IL10, basic FGF2, GCSF, GMCSF, IFN $\gamma$, IP10, MCP1, MIP1 $\alpha$, MIP1 $\beta$, PDGFB, TNF $\alpha$, and VEGFA (15). Furthermore, plasma concentrations of IL2, IL7, IL10, GCSF, IP10, MCP1, MIP1a, and TNFa were shown to be higher in the Intensive Care Unit (ICU) patients than non-ICU patients (15). In addition, according to recent reports, the number of CD4 + and CD8 + T cells in peripheral blood of SARSCoV-2 infected patients are significantly reduced (34).

The pathophysiological mechanisms under the emergence of SARS-CoV-2 have not been fully understood.
However, the genomic similarity of the causative pathogen SARS-CoV-2 with SARS-CoV and MERS-CoV may facilitate the recognition of the COVID-19 and help explain the inflammatory response causing the clinical outcomes with severe pneumonia (28).

\section{CLINICAL PRESENTATION}

The most common signs and symptoms of COVID-19 patients at hospital admission are fever, dry cough, and dyspnea. Other symptoms may consist of fatigue, myalgia, headache, sputum production, and sore throat (38-40). Some case series reported the existence of gastrointestinal symptoms in $2-40 \%$ of the patients $(39,41)$. In comparison, gastrointestinal symptoms such as diarrhea are less common, which shows that its viral tropism is different in comparison with MERS-CoV and SARS-CoV (39).

Three non-peer reviewed expert body press releases from the United States of America, United Kingdom, and France suggested that based on anecdotal emerging clinical observations, changes in olfactory sensations such as anosmia and hyposmia could be clinical features of COVID-19, especially in early or mild cases (42-44). Olfactory or taste disorders were recorded in up to $53 \%$ of the cases in a study from Italy (45). Although the preliminary current evidence for anosmia and hyposmia to be considered as potential clinical features of COVID-19 is inconclusive at the moment, they are proposed as new criteria for testing, especially in young people with few other symptoms (40).

According to the literature, the median incubation period was estimated to be 5.1 days and people may develop symptoms 2-14 days after the exposure to the virus $(46,47)$. Furthermore, the study conducted by Lauer et al. (46) has stated that $97.5 \%$ of infected people show symptoms in 11.5 days.

According to a study of case series from China, the most common laboratory abnormalities observed among their patients were elevated lactate dehydrogenase, depressed total lymphocytes, and prolonged prothrombin time (48). The laboratory abnormalities imply that SARS-CoV-2 infection may correlate with hepatic, renal and myocardial injury, coagulation activation, and immune deficiency. These abnormalities were found to be similar to the abnormalities that were seen at patients infected with MERS-CoV and SARS$\mathrm{CoV}$ (48).

Another study of case series conducted by Huang et al. (15) has found abnormalities in the chest CT images of all patients. Furthermore, 98\% of the patients infected with the virus presented with bilateral involvement, 
and all patients in the study had pneumonia (15).

The common complications among patients included Acute Respiratory Distress Syndrome (ARDS), acute cardiac injury, RNAaemia, and secondary infections (15). Coinfections of fungi and bacteria were seen in especially severely ill patients (49). Some patients progressed with ARDS and septic shock, which was ultimately followed by multiple organ failure $(15,49)$.

In the course of the disease, the median duration from the inception of the first symptoms to developing dyspnea was 5.0 days, 7.0 days to hospital admission, and 8.0 days to developing ARDS, and for discharged patients, the hospital stay was recorded as 10 days (48).

\section{DIAGNOSIS}

WHO describes COVID-19 patients in three separate case definitions: a suspected case is defined as a patient that shows at least one symptom of acute respiratory illness along with fever and has a history of residence in or travel to a location with reports of community transmission of COVID-19 in at least two weeks prior to symptom onset, or a patient with acute respiratory illness and is yet to receive an alternative diagnosis that fully covers the clinical findings (50). A probable case is described as a suspected case for whom the laboratory tests are reported inconclusive or a suspected case for whom testing could not be performed (50). A case can only be defined as positive when a person's laboratory tests return positive for the SARS-CoV-2 infection (50).

Nucleic acid detection in respiratory tract samples in a real-time polymerase chain reaction (RT-PCR) and next-generation sequencing is the forerunning and the most essential method of SARS-CoV detection, in virtue of its commercial viability and relatively short return time $(51,52)$. Specific probes and primers were designed, utilizing the genome sequence of the virus to help accelerate the development of RT-PCR diagnostics (53). The first open reading frames (ORF 1a and $1 b$ ), RNA-dependent RNA polymerase gene, envelope, and nucleocapsid are the main focus for novel coronavirus detection and diagnosis at the moment $(51,53)$. Many in-house assays have been developed or are under development (54). However, this method is not without its shortcomings since RT-PCR has high false-negative rates as well as low detection rates. Furthermore, RTPCR cannot be used to determine the progression or the severity of the disease $(52,55,56)$. In addition, the collection of nasopharyngeal, oropharyngeal samples requires close contact between the patient and the healthcare worker which may lead to further transmission of the disease (57).
Chest X-Rays (CXR) usually do not give specific results as bilateral infiltrates seen in CXR may be normal in early disease (58). Another detection method is computed tomography (CT), which is more sensitive and plays an important role in the clinical detection of COVID-19 $(55,56)$. Ground glass opacities in multifocal lung lesions are typical findings from chest CTs of COVID-19 patients. Investigations of such common symptoms appear to have higher rates of detection than the nucleic acid tests, as well as having the ability to see the severity and track the progression of the disease (52). However, CTs are not commercially viable and not able to identify the specific virus causing the symptoms (55).

Antibody assays can also be an actor in the diagnosis of the COVID-19, albeit as complementary for the viral nucleic acid test $(59,60)$. The primary method of antibody tests is enzyme-linked immunosorbent assay (ELISA) and studies have shown that IgM, IgG, and IgA antibodies can be observed as early as four days after symptom onset. Detection by IgM seroconversion led to higher rates of accurate diagnosis than those of PCR assays five days after symptom onset (59). The detection rates increased significantly when IgM ELISA assay was applied along with a PCR test for each patient $(59,60)$.

\section{CLINICAL MANAGEMENT}

Although patients experiencing mild symptoms do not necessarily need hospital admission, it is still very important to implement applicable infection prevention and control measures in order to contain transmission (61). Following the doctors' and health care guidelines' recommendations, this could be done either in the hospital or at home. Patients with mild illness may be treated with symptomatic treatments such as prescribing antipyretics to manage their fever (61).

When it comes to patients with hypoxemia, severe acute respiratory illness (SARI) and respiratory distress, or shock, these patients should be provided with supplemental oxygen therapy immediately (61). Adults with emergency signs such as absent or obstructed respiration, central cyanosis, severe respiratory distress, shock, convulsions, or coma have to receive airway management and oxygen therapy (61). Patients with COVID-19 should be monitored closely for signs of clinical deterioration and should be intervened with attainable supportive care instantly if necessary (61). The vital signs of patients that have been admitted to the hospital need to be observed consistently. Early warning scores may be used to determine the status 
of the patients and can be beneficial to recognize the deterioration of their condition (62). It is important to keep in mind that aggressive fluid resuscitation might worsen oxygenation, therefore health care staff should be careful while administering patients with SARI with intravenous fluid treatments (63). It is also crucial to consider that patients with ARDS might still experience hypoxemia even when oxygen is delivered with a mask accompanied by a reservoir bag (61).

Deterioration into septic shock is very dangerous, therefore all patients should be monitored closely in order to recognize the signs of septic shock and get ahead with early interventions. The advised care for septic shock patients includes antimicrobial treatment, fluid bolus therapy, and implementing vasopressors within the first hour of septic shock recognition (64).

Taking into account that asymptomatic transmission of the disease may also occur among pregnant and/ or recently pregnant women, health care professionals should observe all women who have a history of contact thoroughly (61). All pregnant women recently diagnosed or women who have recovered from the disease shall be given necessary instructions regarding how to feed their infants safely and regarding appropriate measures to prevent transmission (61).

There have been comparably fewer cases reported of infants as confirmed cases. Additionally, infected infants have reportedly experienced mild symptoms (61). According to the literature, there is not yet any documentation of vertical transmission (61). According to the data from WHO, amniotic fluid sample from six mothers who were positive for SARS-CoV-2 were all negative for the virus. Moreover, the throat swabs and cord blood taken from their neonates also tested negative for the virus (61). Furthermore, the samples that were taken from the mothers' breast milk after the primary lactation were all negative for the virus $(65,66)$. Mothers whom are considered as suspected, probable, or confirmed cases, should feed their infants consistently in accordance with the advised guidelines for feeding their infants while taking necessary precautions to prevent any transmissions (61).

\section{PROGNOSIS}

\section{Intensive care unit}

A study comprising 138 hospitalized patients revealed that organ dysfunction developed in approximately $25 \%$ of the patients who were later transferred to the ICU (48). Patients admitted to the ICU have been reported to have a higher median age and to be more likely to have underlying diseases such as diabetes or hypertension, compared to patients who did not receive intensive care (48).

Patients treated in the ICU were found to be more likely to have pharyngeal pain, dyspnea, dizziness, abdominal pain, anorexia, and many laboratory abnormalities, compared to patients that have not been admitted to the ICU (48).

Several complications may occur in critical patients who receive intensive care as the disease progresses. These complications include ARDS, acute cardiac injury, shock, arrhythmia, acute kidney injury, secondary infections, and RNAaemia $(15,48)$.

\section{Comorbidities}

The elderly and people with underlying comorbidities are the main risk groups for having poor prognosis $(48,67)$. In a study with COVID-19 patients, Wang et al. (48) stated that $46.4 \%$ of patients had one or more accompanying medical conditions including hypertension (31.2\%), cardiovascular disease (14.5\%), diabetes (10.1\%) and malignancy (7.2\%).

Lippi et al. (68) have found that patients with hypertension had approximately 2.5 times higher risk of developing a severe illness or risk of mortality, especially in older individuals. In addition, the chronic obstructive pulmonary disease has been found to carry more than a 5-fold higher risk of severe illness or death and chronic kidney disease more than 3-fold higher risk $(69,70)$.

\section{Elderly people}

The median duration from the onset of the first symptoms to death of patients over 70 years old is 11.5 days, which indicates the vulnerability of the elderly towards SARS-CoV-2 (71). If a patient is not considered old or immunocompromised, the patient may not develop fever, which is one of the most typical symptoms of COVID-19 (72).

Chen et al. (49) have conducted a study on 99 patients with COVID-19 and found that older men with comorbidities are more likely to be affected by COVID-19, leading to serious and even fatal respiratory diseases such as ARDS.

The response of the immune system to previously exposed pathogens is more conserved than its response to never-exposed pathogens. On the contrary, there is a large number of pure $\mathrm{T}$ cells ready to be educated by new pathogens in children who have encountered relatively few pathogens. This may explain the more severe 
course and higher mortality of COVID-19 in the elderly compared to children (73).

As a result, if the innate immune system fails to produce an adequate adaptive response (i.e. virus-specific CD8 + T cells), it can be said that persistent self-induced inflammation can cause mortality in risk groups such as the elderly, with associated comorbidities or immunosuppressed (73).

\section{Children}

Children are susceptible to respiratory system infections because their immune system is yet immature, which results in more diverse symptoms. Therefore, issues like the formation of antibodies or cross-immunity can be easily overlooked (74). SARS-CoV-2 is mainly transmitted among children by close contact and respiratory droplets, similar to adults (74).

It has been reported that COVID-19 progresses significantly milder in neonates, infants, and children compared to adults (9). In a study conducted on 34 children, all the patients were either asymptomatic (9\%) or had mild symptoms, and there were no critical cases or deaths. Fever (50\%) and cough (38\%) were the most common symptoms, and all patients recovered with symptomatic treatment (75). However, with the spread of the outbreak, the number of infected children has increased gradually (74). There have also been critical cases among children, one of these cases were reported in China, describing a child with severe pneumonia and multiorgan dysfunction (76).

\section{Pregnant women}

Pregnant women are more susceptible to respiratory pathogens, and due to high levels of estrogen and progesterone during pregnancy, the upper respiratory tract tends to swell (77).

In addition, pregnant women are in the pro-inflammatory state especially in their first and third trimester, therefore, cytokine storm caused by COVID-19 can lead to a more severe inflammatory condition (78). Although current evidence does not support intrauterine ventral transmission, perinatal SARS-CoV-2 infection can affect the developing fetus and postpartum life (66, 77). Perinatal COVID-19 may also have negative consequences such as abortion, fetal growth restriction, preterm birth, premature rupture of membranes, fetal distress, respiratory distress, thrombocytopenia accompanied by abnormal liver function, and maternal death $(65,66)$.
Further efforts should be made to protect both mothers and fetuses during the ongoing outbreak. In the first and second trimesters, it is necessary to investigate pregnant women with COVID-19 and carefully monitor all infected women during pregnancy and after birth (77).

\section{PREVENTION}

In the fight against COVID-19, exercising necessary precautions is highly crucial in order to contain the spread of infection. Social distancing, self-isolation, hand washing, surface cleaning, and use of personal protective equipment are some of these measures (79, $80)$.

SARS-CoV-2 is a virus that is mainly transmitted through close contact and respiratory droplets. High-risk groups, especially older people and those with chronic diseases, should avoid public places to protect themselves. It is also important for everyone to maintain a social distancing of at least 1 meter (81). Hands must be washed at least 20 seconds after being in public areas or touching surfaces possibly containing the virus. If water and soap are not accessible, hand sanitizer that includes at least $60 \%$ alcohol is recommended (80).

Quarantine is used to keep someone who might have been affected by the SARS-CoV-2 away from others. As for isolation is used to separate sick people from healthy people. Some individuals may not show symptoms even though they are sick. Individuals in this situation may cause the disease to spread without realizing it (82). Those who are carriers or potential carriers of the disease should remain in quarantine. These individuals should be detected and isolated immediately (82).

Another issue is face masks, coverings, and their usage. Taking the highly contagious nature of the disease into consideration, it is advised for everyone to use face coverings in public places (80). This will help to protect other people from sick and/or asymptomatic individuals. Masks, especially high-level masks like the N95, are recommended to be reserved for healthcare workers since they are in more direct contact with sick people compared to the general population (83). Even though the usage of face masks is advised for the public, it is important to emphasize that face masks do not provide full protection and can even increase the risk of infection if not used properly (84).

Healthcare workers have an increased risk of being infected with the virus. Therefore, all healthcare workers require full personal protective equipment including a face shield, isolation gown, gloves, and mask. Medical applications such as tracheostomy, tracheal 
intubation, bronchoscopy, open airway suctioning, high flow oxygen therapy, and autopsy are considered as aerosol-generating medical applications (85). While performing an aerosol-generating medical procedure, the N95 mask must be used. The N95 masks prevent $95 \%$ of droplets from entering through the mask and significantly decrease the risk of getting infected (85).

\section{CONCLUSION}

According to the Situation Report of the WHO that was released on 27 April 2020, there are nearly 3 million confirmed cases and approximately 200.000 deaths due to the COVID-19 pandemic. The United States of America is the country with the most confirmed cases and highest death rates according to the current data (16).

The studies for the development of a vaccine are still ongoing. The research and development landscape of the global COVID-19 vaccine contains 115 candidates. According to the literature, 78 of those candidates are confirmed as active and 37 are yet to be confirmed. In addition, 73 of the 78 confirmed active projects are currently at exploratory or preclinical stages. Besides, many others declared plans to start human testing in 2020 (86).

There are some simple but effective steps to follow offered by WHO to stop the spread of COVID-19 around the world. Those steps are washing hands frequently, maintaining social distancing of at least 1 meter to avoid droplets from coughs and sneezes, averting touching eyes, nose, and mouth and practicing respiratory hygiene which means covering your mouth and nose with your bent elbow or tissue when coughed or sneezed and discarding of the used tissue. The last step to follow is if you have shown all of the symptoms, you should seek medical care immediately. The point of this is to avoid a lethal outcome for yourself and to restrict the circulation of the virus (81).

In the past 50 years, there have been many cases of coronaviruses affecting humans and animals and it is highly possible that new types of coronavirus will emerge in the future (87). To overcome the burdens and outcomes of such infectious diseases, open communication, and collaboration among the international community are highly essential. In conclusion, the COVID-19 pandemic emphasizes the importance of public health management, investment in scientific research, and the immense need for global cooperation.

\section{Ethics Committee Approval: N/A}

\section{Informed Consent: N/A}

Conflict of Interest: The authors declared no conflict of interest. Author contributions: Concept: BK Supervision: BK Resources: BK, SS, OŞ, SK, MYA Materials: BK, SS, OŞ, SK, MYA Data collection and/or processing: BK, SS, OŞ, SK, MYA Analysis and/or Interpretation: BK, SS, OŞ, SK, MYA Literature Search: BK, SS, OŞ, SK, MYA Writing Manuscript: BK, SS, OŞ, SK, MYA Critical Review: BK

Financial disclosure: The authors declared that this study received no financial support.

Editor in chief's Note: Five authors of this article, Beliz Koçyiğit, Sezin Sayın, Fevzi Oktay Şişman, Sarper Kızılkaya and Mert Yücel Ayrik are members of the editorial board of Turkish Medical Student Journal. However, they did not take place in any stage of the editorial decision of the manuscript. The editors who evaluated this manuscript are from other institutions.

\section{REFERENCES}

1. Gorbalenya AE, Baker SC, Baric RS et al. The species severe acute respiratory syndrome-related coronavirus: classifying 2019-nCoV and naming it SARS-CoV-2. Nat Microbiol 2020;5(4):536-44.

2. Lu H, Stratton CW, Tang YW. Outbreak of pneumonia of unknown etiology in Wuhan, China: The mystery and the miracle. J Med Virol 2020;92(4):401- 2.

3. Bogoch A, Watts A, Thomas-Bachli C et al. Pneumonia of unknown etiology in Wuhan, China: potential for international spread via commercial air travel. J Trav Med 2020;27(2):1-3.

4. World Health Organization (WHO). "Statement on the second meeting of the International Health Regulations (2005) Emergency Committee regarding the outbreak of novel coronavirus (2019-nCoV)". (cited 2020 April 10) Available from: URL: https:// www.who.int/news-room/detail/30-01-2020-statement-on-the-second-meeting-of-the-international-health-regulations-(2005)-emergency-committee-regarding-the-outbreak-of-novel-coronavirus-(2019-ncov)

5. World Health Organization (WHO) "WHO Director-General's opening remarks at the media briefing on COVID-19-11 March 2020". (cited 2020 April 11) Available from: URL: https://www.who. $\mathrm{int} / \mathrm{dg} /$ speeches/detail/who-director-general-s-opening-remarks-atthe-media-briefing-on-covid-19---11-march-2020

6. Kakodkar P, Kaka N, Baig MN. A comprehensive literature review on the clinical presentation, and management of the pandemic coronavirus disease 2019 (COVID-19). Cureus 2020;12(4):e7560.

7. Adhikari S, Meng S, Wu Y et al. Epidemiology, causes, clinical manifestation and diagnosis, prevention and control of coronavirus disease (COVID-19) during the early outbreak period: a scoping review. Infect Dis Poverty 2020;29(9).

8. Li G, Fan Y, Lai Y et al. Coronavirus infections and immune responses. J Med Virol 2020;92(4):424-32. 
9. Singhal T. A review of coronavirus disease-2019 (COVID-19). Indian J Pediatr 2020;87(4):281-6.

10. Guo YR, Cao QD, Hong ZS et al. The origin, transmission and clinical therapies on coronavirus disease 2019 (COVID-19) outbreak - an update on the status. Mil Med Res 2020;7(1):11.

11. Sun P, $\mathrm{Lu} \mathrm{X}, \mathrm{Xu} \mathrm{C}$ et al. Understanding of COVID-19 based on current evidence. J Med Virol 2020 Feb 25 doi:10.1002/jmv.25722 [Epub ahead of print]

12. Lake MA. What we know so far: COVID-19 current clinical knowledge and research. Clin Med (Lond) 2020;20(2):124-7.

13. World Health Organization (WHO) COVID-19 Timeline (cited 2020 April 12) Available from: URL: https://www.who.int/news-room/detail/08-04-2020-who-timeline---covid-19

14. Zhou P, Yang XL, Wang XG et al. A pneumonia outbreak associated with a new coronavirus of probable bat origin. Nature 2020;579(7798):270-3

15. Huang C, Wang Y, Li X et al. Clinical features of patients infected with 2019 novel coronavirus in Wuhan, China. Lancet 2020;395(10223):497-506.

16. World Health Organization (WHO) Coronavirus disease 2019 (COVID-19) Situation Report-98 (cited 2020 April 27) Available from: URL: https://www.who.int/docs/default-source/coronaviruse/situation-reports/20200427-sitrep-98-covid-19.pdf?sfvrsn $=90323472 \_4$

17. Tang JW, Li Y, Eames I et al. Factors involved in the aerosol transmission of infection and control of ventilation in healthcare premises. J Hosp Infect. 2006;64(2):100-14.

18. Centers for Disease Control and Prevention (CDC). How COVID-19 spreads? (cited 2020 April 28) Available from: URL: https:// www.cdc.gov/coronavirus/2019-ncov/prevent-getting-sick/how-covid-spreads.html

19. World Health Organization (WHO) Report of the WHO-China joint mission on coronavirus disease 2019 (COVID-19) (28 February 2020) (cited 2020 April 2) Available from: URL: https://www.who. int/docs/default-source/coronaviruse/who-china-joint-mission-oncovid-19---final-report-1100hr-28feb2020-11mar-update.pdf?sfvrs$\mathrm{n}=1 \mathrm{a} 13 \mathrm{fda} 0 \_2 \&$ download=true

20. Rothe C, Schunk M, Sothmann P et al. Transmission of 2019$\mathrm{nCoV}$ infection from an asymptomatic contact in Germany. N Engl J Med 2020;382(10):970-1.

21. Centers for Disease Control and Prevention (CDC). People who are at higher risk for severe illness? (cited 2020 May 1) Available from: URL: https://www.cdc.gov/coronavirus/2019-ncov/need-extra-precautions/people-at-higher-risk.html

22. Garg S, Kim L, Whitaker M et al. Hospitalization rates and characteristics of patients hospitalized with laboratory-confirmed coronavirus disease 2019 - COVID-NET, 14 States, March 1-30, 2020. MMWR Morb Mortal Wkly Rep 2020;(69):458-64.

23. Zhu N, Zhang D, Wang W et al. A novel coronavirus from patients with pneumonia in China, 2019. N Engl J Med 2020;382(8):727-33.

24. Forni D, Cagliani R, Clerici M et al. Molecular evolution of human coronavirus genomes. Trends Microbiol 2017;25(1):35-48.
25. Lu R, Zhao X, Li J at al. Genomic characterization and epidemiology of 2019 novel coronavirus: implications for virus origins and receptor binding. Lancet 2020;395(10224):565-74.

26. Wu F, Zhao S, Yu B et al. A new coronavirus associated with human respiratory disease in China. Nature 2020;579(7798):265-9.

27. Cheng ZJ, Shan J. 2019 Novel coronavirus: where we are and what we know. Infection 2020;48(2):155-63.

28. Fehr AR, Perlman S. Coronaviruses: an overview of their replication and pathogenesis. Methods Mol Biol 2015;1282:1-23.

29. Wrapp D, Wang N, Corbett KS et al. Cryo-EM structure of the 2019-nCoV spike in the prefusion conformation. Science 2020;367(6483):1260-3.

30. Perlman S, Netland J. Coronaviruses post-SARS: update on replication and pathogenesis. Nat Rev Microbiol 2009;7(6):439-50.

31. de Wit E, van Doremalen N, Falzarano D et al. SARS and MERS: recent insights into emerging coronaviruses. Nat Rev Microbiol 2016;14(8):523-34.

32. Lei J, Li J, Li X et al. CT Imaging of the 2019 novel coronavirus (2019-nCoV) pneumonia. Radiology 2020;295(1):18.

33. Peiris JS, Guan Y, Yuen KY. Severe acute respiratory syndrome. Nat Med 2004;10(12 Suppl):88-97.

34. Xu Z, Shi L, Wang Y et al. Pathological findings of COVID-19 associated with acute respiratory distress syndrome. Lancet Respir Med 2020;8(4):420-2.

35. Williams AE, Chambers RC. The mercurial nature of neutrophils: still an enigma in ARDS? Am J Physiol Lung Cell Mol Physiol 2014;306(3):217-30.

36. Channappanavar R, Perlman S. Pathogenic human coronavirus infections: causes and consequences of cytokine storm and immunopathology. Semin Immunopathol 2017;39(5):529-39.

37. Cameron MJ, Bermejo-Martin JF, Danesh A et al. Human immunopathogenesis of severe acute respiratory syndrome (SARS). Virus Res 2008;133(1):13-9.

38. Lai CC, Shih TP, Ko WC et al. Severe acute respiratory syndrome-coronavirus-2 (SARS-CoV-2) and corona virus disease-2019 (COVID-19): the epidemic and the challenges. Int J Antimicrob Agents 2020;55(3):105924.

39. Guan WJ, Ni ZY, Hu Y et al. Clinical characteristics of Coronavirus Disease 2019 in China. N Engl J Med 2020;382(18):1708-20.

40. Vetter P, Vu DL, L'Huillier AG et al. Clinical features of covid-19. BMJ 2020;369:1470.

41. Zhang JJ, Dong X, Cao YY et al. Clinical characteristics of 140 patients infected with SARS-CoV-2 in Wuhan. Allergy 2020 Feb 19 doi:10.1111/all.14238 [Epub ahead of print]

42. ENT-UK. Loss of sense of smell as marker of COVID-19 infection. (cited 2020 March 23) Available from: URL: https://www.entuk. org/sites/default/files/files/Loss\%20of\%20sense \%20of\%20smell\%20 as\%20marker\%20of\%20COVID.pdf.

43. American Academy of Otolaryngology - Head and Neck Surgery (AAO-HNS). Anosmia, Hyposmia, and Dysgeusia Symptoms of Coronavirus Disease. (cited 2020 April 22) Available from: URL: https:// www.entnet.org/content/aao-hns-anosmia-hyposmia-and-dysgeusia-symptoms-coronavirus-disease. 
44. French ENT Society (SFORL) Press release. Alerte Anosmie COVID-19. (cited 2020 March 20) Available from: URL: https://www. sforl.org/wp-content/uploads/2020/03/Alerte-anosmie-COVID-19. pdf.

45. Giacomelli A, Pezzati L, Conti F et al. Self-reported olfactory and taste disorders in SARS-CoV-2 patients: a cross-sectional study. Clin Infect Dis 2020 March 26 doi:10.1093/cid/ciaa330 [Epub ahead of print]

46. Lauer SA, Grantz KH, Bi Q et al. The incubation period of coronavirus disease 2019 (covid-19) from publicly reported confirmed cases: estimation and application. Ann Intern Med 2020 March 10 doi: 10.7326/M20-0504 [Epub ahead of print]

47. Centers for Disease Control and Prevention (CDC). Symptoms of Coronavirus. (cited 2020 March 20) Available from: URL: https:// www.cdc.gov/coronavirus/2019-ncov/symptoms-testing/symptoms. html.

48. Wang D, Hu B, Hu C et al. Clinical characteristics of 138 hospitalized patients with 2019 novel coronavirus-infected pneumonia in Wuhan, China. JAMA. 2020 Feb 7. doi: 10.1001/jama.2020.1585. [Epub ahead of print].

49. Chen N, Zhou M, Dong X et al. Epidemiological and clinical characteristics of 99 cases of 2019 novel coronavirus pneumonia in Wuhan, China: a descriptive study. Lancet. 2020;395(10223):507-13. 50. World Health Organization (WHO) Interim guidance. Global surveillance for COVID-19 caused by human infection with COVID-19 virus. (cited on 2020 March 20) Available from: URL: https://www.who.int/publications-detail/global-surveillance-for-covid-19-caused-by-human-infection-with-covid-19-virus-interim-guidance .

51. Ahn DG, Shin HJ, Kim MH et al. Current status of epidemiology, diagnosis, therapeutics, and vaccines for novel coronavirus disease 2019 (COVID-19). J Microbiol Biotechnol 2020;30(3):313-24.

52. Tu H, Tu S, Gao S et al. The epidemiological and clinical features of COVID-19 and lessons from this global infectious public health event. J Infect 2020 Apr 18 doi:10.1016/j.jinf.2020.04.011 [Epub ahead of print]

53. Corman VM, Landt O, Kaiser M et al. Detection of 2019 novel coronavirus (2019-nCoV) by real-time RT-PCR. Euro Surveill 2020;25(3):2000045.

54. World Health Organization (WHO). Laboratory testing for coronavirus disease 2019 (COVID-19) in suspected human cases (cited 2020 April 27) Available from: URL: https://apps.who.int/iris/handle/10665/331329.

55. Li Y, Xia L. Coronavirus Disease 2019 (COVID-19): Role of chest CT in diagnosis and management. AJR Am J Roentgenol 2020 Mar 4. doi: 10.2214/AJR.20.22954. [Epub ahead of print]

56. Feng H, Liu Y, Lv M et al. A case report of COVID-19 with false negative RT-PCR test: necessity of chest CT. Jpn J Radiol 2020;38(5):409-10.

57. To KK, Tsang OT, Chik-Yan Yip C et al. Consistent detection of 2019 novel coronavirus in saliva. Clin Infect Dis 2020 Feb 12. doi: 10.1093/cid/ciaa149. [Epub ahead of print]

58. Tapé C, Byrd KM, Aung S et al. COVID-19 in a Patient Presenting with Syncope and a Normal Chest X-ray. R I Med J 2020;103(3):50-1.
59. Guo L, Ren L, Yang S et al. Profiling early humoral response to diagnose novel coronavirus disease (COVID-19). Clin Infect Dis 2020 Mar 21 doi: 10.1093/cid/ciaa310. [Epub ahead of print] 60. Xiang F, Wang X, He X et al. Antibody detection and dynamic characteristics in patients with COVID-19. Clin Infect Dis $2020 \mathrm{Apr}$ 19. doi: 10.1093/cid/ciaa461. [Epub ahead of print]

61. World Health Organization (WHO). Clinical management of severe acute respiratory infection (SARI) when COVID-19 disease is suspected (cited 2020 April 27) Available from: URL: https:// www.who.int/publications-detail/clinical-management-of-severe-acute-respiratory-infection-when-novel-coronavirus-(ncov)-infection-is-suspected.

62. Abbott TE, Vaid N, Ip D et al. A single-centre observational cohort study of admission National Early Warning Score (NEWS). Resuscitation 2015;92:89-3.

63. Schultz MJ, Dunser MW, Dondorp AM et al. Current challenges in the management of sepsis in ICUs in resource-poor settings and suggestions for the future. Intensive Care Med 2017;43(5):612-24.

64. Rhodes A, Evans LE, Alhazzani W et al. Surviving sepsis campaign: international guidelines for management of sepsis and septic shock: 2016. Intensive Care Med 2017;43(3):304-77.

65. Zhu H, Wang L, Fang C et al. Clinical analysis of 10 neonates born to mothers with 2019-nCoV pneumonia. Transl Pediatr 2020;9(1):51-60.

66. Chen $\mathrm{H}$, Guo J, Wang $\mathrm{C}$ et al. Clinical characteristics and intrauterine vertical transmission potential of COVID-19 infection in nine pregnant women: a retrospective review of medical records. Lancet 2020;395(10226):809-15.

67. Yang X, Yu Y, Xu J et al. Clinical course and outcomes of critically ill patients with SARS-CoV-2 pneumonia in Wuhan, China: a single-centered, retrospective, observational study. Lancet Respir Med 2020 Feb 24. doi: 10.1016/S2213-2600(20)30079-5. [Epub ahead of print]

68. Lippi G, Wong J, Henry BM. Hypertension and its severity or mortality in coronavirus disease 2019 (COVID-19): a pooled analysis. Pol Arch Intern Med 2020 Mar 31. doi: 10.20452/pamw.15272. [Epub ahead of print]

69. Lippi G, Henry BM. Chronic obstructive pulmonary disease is associated with severe coronavirus disease 2019 (COVID-19). Respir Med 2020 Mar 24. doi: 10.1016/j.rmed.2020.105941. [Epub ahead of print]

70. Henry BM, Lippi G. Chronic kidney disease is associated with severe coronavirus disease 2019 (COVID-19) infection. Int Urol Nephrol 2020 Mar 28. doi: 10.1007/s11255-020-02451-9. [Epub ahead of print]

71. Sohrabi C, Alsafi Z, O'Neill N et al. World Health Organization declares global emergency: A review of the 2019 novel coronavirus (COVID-19). Int J Surg 2020;76:71-6.

72. Zhou M, Zhang X, Qu J. Coronavirus disease 2019 (COVID-19): a clinical update. Front Med 2020 Apr 2. doi: 10.1007/s11684-0200767-8. [Epub ahead of print]

73. Ahmadpoor P, Rostaing L. Why the immune system fails to mount an adaptive immune response to a COVID-19 infection. Transpl Int 2020 Apr 1. doi: 10.1111/tri.13611. [Epub ahead of print] 
74. Huang X, Wei F, Hu L et al. Epidemiology and clinical characteristics of COVID-19. Arch Iran Med. 2020;23(4):268-71.

75. Wang XF, Yuan J, Zheng YJ et al. Clinical and epidemiological characteristics of 34 children with 2019 novel coronavirus infection in Shenzhen. Zhonghua Er Ke Za Zhi 2020;58:E008.

76. Chen F, Liu ZS, Zhang FR et al. First case of severe childhood novel coronavirus pneumonia in China. Zhonghua Er Ke Za Zhi. 2020;58:E005.

77. Liu H, Wang LL, Zhao SJ et al. Why are pregnant women susceptible to COVID-19? An immunological viewpoint. J Reprod Immunol 2020 Mar 19. doi: 10.1016/j.jri.2020.103122. [Epub ahead of print]

78. Mor G, Aldo P, Alvero AB. The unique immunological and microbial aspects of pregnancy. Nat Rev Immunol. 2017;17(8):469-82.

79. Public Health Ontario. IPAC recommendations for use of personal protective equipment for care of individuals with suspect or confirmed COVID-19. (cited 2020 April 26) Available from: URL: https://www.publichealthontario.ca/-/media/documents/ncov/updated-ipac-measures-covid-19.pdf?la=en.

80. Centers for Disease Control and Prevention (CDC). How to protect yourself \& others? (cited 2020 April 26) Available from: URL: https://www.cdc.gov/coronavirus/2019-ncov/prevent-getting-sick/ prevention.html.

81. World Health Organization (WHO). Coronavirus disease (COVID-19) advice for the public. (cited 2020 April 21) Available from: URL: https://www.who.int/emergencies/diseases/novel-coronavirus-2019/advice-for-public.

82. Gandhi M, Yokoe DS, Havlir DV. Asymptomatic transmission, the Achilles' heel of current strategies to control COVID-19. N Engl J Med 2020 Apr 24 doi: 10.1056/NEJMe2009758 [Epub ahead of print] 83. Centers for Disease Control and Prevention (CDC). Use of cloth face coverings to help slow the spread of COVID-19. (cited 2020 April 26) Available from: URL: https://www.cdc.gov/coronavirus/2019-ncov/prevent-getting-sick/diy-cloth-face-coverings.html.

84. World Health Organization (WHO). Coronavirus disease (COVID-19) advice for the public: When and how to use masks. (cited 2020 May 4) Available from: URL: https://www.who.int/emergencies/diseases/novel-coronavirus-2019/advice-for-public/when-andhow-to-use-masks.

85. Public Health Ontario. Ontario Agency for Health Protection and Promotion, Provincial Infectious Diseases Advisory Committee. Routine Practices and Additional Precautions in All Health Care Settings. 3rd edition. Toronto, ON: Queen's Printer for Ontario; November 2012. (cited 2020 April 26) Available from: URL: https://www. publichealthontario.ca/-/media/documents/b/2012/bp-rpap-healthcare-settings.pdf?la=en.

86. Thanh Le T, Andreadakis Z, Kumar A et al. The COVID-19 vaccine development landscape. Nat Rev Drug Discov 2020 Apr 9. doi: 10.1038/d41573-020-00073-5. [Epub ahead of print]

87. Unhale SS, Bilal Q, Sanap S et al. A review on coronavirus (COVID-19). International Journal of Pharmaceutical and Life Sciences 6(4):109 - 15 . 